\title{
RESOLUCIÓN 1820 DEL CONSEJO DE SEGURIDAD
}

\section{DEClARACIÓN DE LA PRESIDENCIA DEL CONSEJO DE SEGURIDAD*}

En la 5936a. sesión del Consejo de Seguridad, celebrada el 17 de julio de 2008, en relación con el examen por el Consejo del tema titulado "Los niños y los conflictos armados", el presidente del Consejo de Seguridad formuló la siguiente declaración en nombre del Consejo:

El Consejo de Seguridad reitera su compromiso de abordar las amplias repercusiones de los conflictos armados en los niños y su determinación de asegurar que se respeten y apliquen la resolución 1612 (2005) y todas sus resoluciones anteriores sobre los niños y los conflictos armados, así como las declaraciones de su Presidencia del 24 de julio 2006 (S/PRST/2006/33), 28 de noviembre de 2006 (S/PRST/2006/48) y 12 de febrero de 2008 (S/PRST/2008/6), que proporcionan un marco amplio para abordar la protección de los niños afectados por los conflictos armados, al igual que las disposiciones relativas a los niños que figuran en otras resoluciones, entre ellas las resoluciones 1325 (2000), 1674 (2006) y 1820 (2008).

El Consejo de Seguridad reitera su enérgica e invariable condena de la continuación del reclutamiento y la utilización de niños en los conflictos armados en contravención del derecho internacional aplicable, así como el asesinato y la mutilación de niños, las violaciones y otros tipos de violencia sexual, los secuestros, la denegación del acceso humanitario a los niños y los ataques contra escuelas y hospitales que llevan a cabo las partes en los conflictos armados, si bien, reconoce que con la aplicación de su resolución 1612 (2005) ya ha habido progresos, como resultado de los cuales se ha liberado a niños que han sido reintegrados a sus familias y comunidades, mediante, entre otras cosas, un diálogo más sistemático entre los equipos de tareas de las Naciones Unidas en los países y las partes en los conflictos armados respecto de la puesta en práctica de planes de acción con plazos.

* Consejo de Seguridad, distribución general, original en inglés, 17 de julio de 2008. 
El Consejo de Seguridad reafirma la necesidad de que los Estados partes cumplan las obligaciones contraídas en virtud de la Convención sobre los Derechos del Niño y sus protocolos facultativos, a fin de que los grupos armados que no pertenecen a las fuerzas del Estado se abstengan de reclutar niños o utilizarlos en las hostilidades, e insta a los Estados que aún no lo hayan hecho a que consideren la posibilidad de ratificar estos instrumentos o adherirse a ellos.

El Consejo de Seguridad acoge con satisfacción la puesta en marcha del mecanismo de supervisión y presentación de informes sobre los niños y los conflictos armados, en particular los esfuerzos que han hecho posible su aplicación en todas las situaciones enumeradas en los anexos del informe más reciente del Secretario General (S/2007/757), e invita al Secretario General a que, cuando proceda, haga aplicar el mecanismo con el máximo grado de eficiencia, de conformidad con lo dispuesto en la resolución 1612 (2005).

El Consejo de Seguridad acoge complacido la actividad continuada de su Grupo de Trabajo sobre la cuestión de los niños y los conflictos armados, según se señala, entre otros, en el último informe de su Presidencia (S/2008/455, anexo) y, habida cuenta de que el mecanismo de supervisión y presentación de informes se está aplicando en un número cada vez mayor de situaciones de conflicto armado, pide al Secretario General que preste mayor apoyo administrativo para que el Grupo de Trabajo siga llevando a cabo plenamente su mandato de manera eficaz.

El Consejo de Seguridad invita a su Grupo de Trabajo sobre los niños y los conflictos armados a que siga adoptando conclusiones que proporcionen a las partes en los conflictos armados y a los agentes internacionales pertinentes una orientación clara sobre las medidas concretas que deben adoptarse a fin de cumplir las obligaciones que les incumben en virtud del derecho internacional, y en particular las resoluciones del Consejo de Seguridad sobre los niños y los conflictos armados, y a que proponga al Consejo recomendaciones eficaces basadas en información oportuna, objetiva, exacta y fiable, con miras a promover la protección de los niños afectados por los conflictos armados, incluso mediante mandatos apropiados de las operaciones de mantenimiento de la paz y misiones políticas de las Naciones Unidas. El Consejo de Seguridad acoge con satisfacción la labor realizada por el Grupo de Trabajo para mejorar sus métodos de trabajo y le alienta a que siga haciéndolo a fin de seguir aumentando su transparencia y eficacia. 
El Consejo de Seguridad encomia la labor llevada a cabo por la Representante Especial del Secretario General para la cuestión de los niños y los conflictos armados, Sra. Radhika Coomaraswamy, y destaca la importancia de sus visitas a los países para facilitar una mejor coordinación entre los asociados de las Naciones Unidas a nivel del terreno, promover la colaboración entre las Naciones Unidas y los gobiernos, mejorar el diálogo con las partes en los conflictos respecto de la observancia del derecho internacional aplicable, incluidas sus obligaciones en virtud de la resolución 1612 (2005) del Consejo de Seguridad, y obtener así compromisos concretos relativos a la protección de los niños.

El Consejo de Seguridad encomia también la labor llevada a cabo por el Fondo de las Naciones Unidas para la Infancia (UNICEF), así como por otros organismos, fondos y programas pertinentes de las Naciones Unidas dentro de sus respectivos mandatos, y por los asesores sobre protección de menores de las operaciones de mantenimiento de la paz y las misiones políticas, en cooperación con los gobiernos nacionales y agentes pertinentes de la sociedad civil, para mejorar las actividades de los equipos de tareas de las Naciones Unidas en los países respecto de la supervisión, la presentación de informes y la promoción de la protección de los niños a nivel del terreno, incluso mediante la aplicación de la resolución 1612 (2005) del Consejo de Seguridad y el seguimiento de las conclusiones pertinentes del Grupo de Trabajo del Consejo de Seguridad sobre los niños y los conflictos armados.

El Consejo de Seguridad reconoce el importante papel de la educación en las zonas de conflictos armados como medio de alcanzar el objetivo de detener e impedir el reclutamiento reiterado de los niños y exhorta a todas las partes interesadas a que sigan velando por que todos los niños asociados con fuerzas armadas y grupos armados, así como las cuestiones relacionadas con los niños, se incluyan sistemáticamente en todo proceso de desarme, desmovilización y reintegración, haciendo especial hincapié en la educación.

El Consejo de Seguridad reitera la necesidad de que todas las partes interesadas, incluidos los gobiernos y la comunidad de donantes, se concentren con mayor intensidad en los efectos a largo plazo de los conflictos armados en los niños y en los obstáculos que se interponen a su plena rehabilitación y reintegración en sus respectivas familias y comunidades, entre otras formas, atendiendo a la necesidad de prestarles una atención médica adecuada, mejorando el intercambio de información sobre sus 
programas y mejores prácticas, y garantizando la disponibilidad de recursos, fondos y asistencia técnica adecuados para prestar apoyo a estrategias o planes de acción nacionales relativos a la protección y el bienestar de los niños así como a programas comunitarios, teniendo presentes los "Compromisos de París para proteger a los niños del reclutamiento o la utilización ilegales por fuerzas o grupos armados", con miras a asegurar la sostenibilidad y el éxito a largo plazo de la respuesta de sus programas a la cuestión de la liberación, rehabilitación y reintegración de todos los niños vinculados a fuerzas armadas y grupos armados.

El Consejo de Seguridad aguarda con interés el próximo informe del Secretario General sobre los niños y los conflictos armados, y reitera su disposición a seguir examinando las disposiciones correspondientes de sus resoluciones sobre los niños y los conflictos armados, sobre la base de lo dispuesto en la resolución 1612 (2005), con miras a seguir mejorando el marco general de protección de los niños en los conflictos armados. 